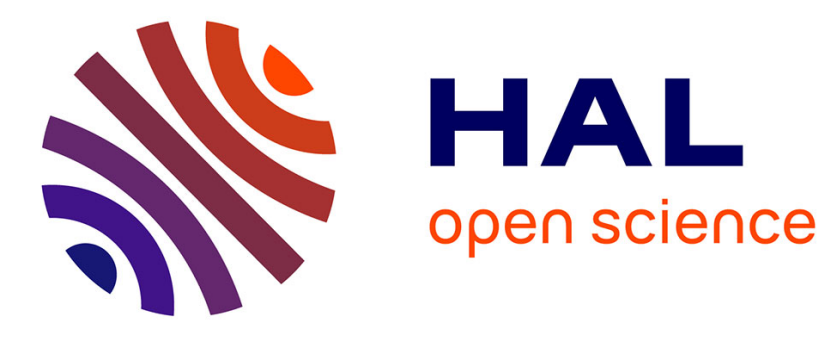

\title{
Cancer mortality after radiotherapy for a skin hemangioma during childhood.
}

Marie-Gabrielle Dondon, Florent de Vathaire, Akhtar Shamsaldin, Françoise Doyon, Ibrahima Diallo, Laurent Ligot, Catherine Paoletti, Martine Labbé, Moncef Abbas, Jean Chavaudra, et al.

\section{To cite this version:}

Marie-Gabrielle Dondon, Florent de Vathaire, Akhtar Shamsaldin, Françoise Doyon, Ibrahima Diallo, et al.. Cancer mortality after radiotherapy for a skin hemangioma during childhood.. Radiotherapy \& Oncology, 2004, 72, pp.87-93. 10.1016/j.radonc.2004.03.011 . inserm-00117150

\section{HAL Id: inserm-00117150 https://www.hal.inserm.fr/inserm-00117150}

Submitted on 14 Feb 2007

HAL is a multi-disciplinary open access archive for the deposit and dissemination of scientific research documents, whether they are published or not. The documents may come from teaching and research institutions in France or abroad, or from public or private research centers.
L'archive ouverte pluridisciplinaire HAL, est destinée au dépôt et à la diffusion de documents scientifiques de niveau recherche, publiés ou non, émanant des établissements d'enseignement et de recherche français ou étrangers, des laboratoires publics ou privés. 


\section{HAL author manuscript}

\section{Cancer mortality after radiotherapy for a skin hemangioma during childhood.}

Marie-Gabrielle Dondon $^{\mathrm{a}}$, Florent de Vathaire ${ }^{\mathrm{a}^{*}}$, Akhtar Shamsaldin ${ }^{\mathrm{a}, \mathrm{b}}$, Françoise Doyon ${ }^{\mathrm{a}}$, Ibrahima Diallo ${ }^{\mathrm{a}, \mathrm{b}}$, Laurent Ligot ${ }^{\mathrm{a}}$, Catherine Paoletti ${ }^{\mathrm{a}}$, Martine Labbé ${ }^{\mathrm{a}}$, Moncef Abbas ${ }^{\mathrm{a}}$, Jean Chavaudra $^{\mathrm{b}}$, Marie-Françoise Avril ${ }^{\mathrm{c}}$, Philippe Fragu ${ }^{\mathrm{d}}$, François Eschwège ${ }^{\mathrm{e}}$.

${ }^{\mathrm{a}}$ INSERM U605, Institut Gustave-Roussy , Villejuif, France

${ }^{\mathrm{b}}$ Department of Medical Physics, Institut Gustave-Roussy, Villejuif, France

${ }^{\mathrm{c}}$ Department of Dermatology, Institut Gustave-Roussy, Villejuif France

${ }^{\mathrm{d}}$ Department of Nuclear Medicine, Institut Gustave-Roussy, Villejuif France

${ }^{\mathrm{e}}$ Department of Radiotherapy, Institut Gustave-Roussy, Villejuif France

27 pages, 11 tables and 1 figure included in the manuscript

Running head: Cancer mortality after radiotherapy

Keywords: hemangioma, childhood, radiation, mortality, cohort

* Corresponding author:

Florent de Vathaire, INSERM U605.

Institut Gustave-Roussy, Rue Camille Desmoulins, 94805 Villejuif, Cedex, France.

Phone: 33.1.42.11.54.57

Fax: 33.1.42.11.53.15

E-mail: fdv@igr.fr. 


\title{
ACKNOWLEDGMENTS
}

This work was supported by the Fondation de France, the Ligue Nationale Contre le Cancer (LNCC) and European Commission contract F14P-CT95-0009. We are grateful to Ziyan Famy for her contribution to this work and to Lorna Saint Ange for editing.

\begin{abstract}
Background and purpose A cohort study was performed as part of a European Radiation Protection Program to investigate the carcinogenic effect of treatment with ionizing radiation in early childhood. This paper presents mortality after radiotherapy in this cohort.

Methods and Materials The cohort comprised 7037 patients under 15 years of age treated for a skin hemangioma between 1940 and 1973 at the Institut Gustave-Roussy, among whom 4940 received radiotherapy. The vital status and causes of death were obtained as well as the mortality rates in the general French population. External and internal analyses were performed. Standardized Mortality Ratio (SMR) and Relative Risk (RR) variations according to exposure to radiotherapy or not and the type of treatment were studied.

Results During the 1969-1997 follow-up period, 16 cohort patients died of cancer, 14 after radiotherapy. A non significant excess of cancer-related mortality was observed for irradiated patients as compared to the general population $(\mathrm{SMR}=1.53 ; 95 \% \mathrm{CI}=0.86-2.48)$. Treatment with ${ }^{226} \mathrm{Ra}$ seemed to play a significant role $(\mathrm{RR}=2.53$; 95\%CI $=0.84-7.07)$ compared to no radiotherapy.
\end{abstract}

Conclusion This study suggests an excess risk of cancer-related mortality in patients treated during early childhood with radiotherapy for skin hemangioma, and especially with ${ }^{226} \mathrm{Ra}$. These patients need to be followed up in the future. 


\section{INTRODUCTION}

Ionizing radiation was used to treat children for skin hemangioma until the end of the fifties in most Western countries [6,12]. The great majority of children were treated with

${ }^{226} \mathrm{Ra}$ tubes, sheets and needles, and a minority received x-ray contact-therapy. The long-term carcinogenic consequences of such treatments are still being studied intensively in Sweden $[6,7,8,11,14,15,16]$, and cohort studies performed for this purpose are now considered one of the major sources of information about the carcinogenic effects of ionizing radiation in infancy.

In France, during the 1940-1973 period, 7826 children below 15 years of age (6 months on average) were treated for skin hemangioma at the Institut Gustave-Roussy. Radiotherapy was delivered using beta, gamma and/or x-rays in 70\% of cases. Several studies [3,5] have investigated the late effects of the different techniques used to treat skin hemangioma but none of them focused on the possible long-term effects of beta applicators. In addition, the previous studies exclusively concerned specific skin and thyroid effects.

In the context of the European Radiation Protection Program (Contract N F14P-CT950009), we decided with Swedish colleagues to constitute the cohort described in this study. The main objective was to describe the hemangioma cohorts in the Karolinska Hospital (Stockholm), Sahlgrenska University Hospital (Gothenberg), and the Institut Gustave-Roussy (Villejuif), placing special emphasis on treatments and dose calculations. The three pooled cohorts were then used to investigate the carcinogenic effect of radiation therapy during early childhood. Individual analyses are also ongoing for each cohort. This paper presents the mortality analysis conducted on the French cohort.

\section{METHODS AND MATERIAL}

\section{Patients}

Information about patients and treatments was extracted from the medical records of the Institut Gustave-Roussy. A total of 8303 patients were verified. Among these patients, 503 were excluded due to the following reasons : 385 had been treated after 15 years of age, 26 had died before 1969, when individual causes of death began to be registered in France, 92 had been treated before 1940, a period during which the exhaustiveness of the IGR medical records cannot be guaranteed.

For the remaining 7800 patients, the vital status of the 7037 included in our analysis was obtained from the National Institute of Statistics and Economic Studies (INSEE). We were unable to obtain the vital status for the other 763 patients who were therefore excluded 
from the analysis. Table 1 shows the characteristics of these two groups. Dose estimation was not completed for $4 \%$ of the study group and $7 \%$ of the excluded patients $(\mathrm{p}=0.05)$. There was no other difference between the two groups.

Initial, immediate and associated causes of death, coded according to the $9^{\text {th }}$ version of the International Classification of Diseases, were obtained from the Center of Epidemiology on Medical Causes of Death at the National Institute of Health and Medical Research (CépiDc INSERM) for every patient who had died during the 1969-1997 period.

\section{Dosimetry}

Of the 7037 patients included, 4940 had received radiotherapy, and 4720 had been treated with radium and $\beta$ - applicators $\left({ }^{32} \mathrm{P},{ }^{90} \mathrm{Sr} /{ }^{90} \mathrm{Y}\right.$ plaques) or interstitial brachytherapy $\left({ }^{226} \mathrm{Ra}\right.$ and ${ }^{90} \mathrm{Y}$ needles) while 568 had been treated with $\mathrm{x}$-rays. Some of these patients (24\%) had received more than one treatment modality. Compared to those who had received radiotherapy, patients who had not were more frequently men (33\% vs $31 \%, \mathrm{p}=0.03$ ), were older at the $1^{\text {st }}$ treatment ( $27 \%$ more than 1 year old vs $14 \%, \mathrm{p}<0.001$ ), but the date of the $1^{\text {st }}$ treatment was similar $(\mathrm{p}=0.8)$.

The treated hemangiomas were located anywhere on the body, but were concentrated in the head, neck, and upper thoracic regions. Radium sheets were initially used as beta sources for superficial skin lesions. Cork layers, mostly $2 \mathrm{~mm}$, were frequently used with radium plaques to reduce beta doses in the immediate vicinity to negligible values compared to the gamma doses. Given the drawbacks and unsatisfactory treatment results obtained with these plaques, radium needles were preferred. Pure beta sources $\left({ }^{32} \mathrm{P},{ }^{90} \mathrm{Sr} /{ }^{90} \mathrm{Y},{ }^{90} \mathrm{Y}\right)$ were introduced for such treatments in the 1950s and gradually replaced the radium sources in order to eliminate the potential effects of their gamma rays. A detailed description of the radioactive applicators has already been published [21]. X-ray treatments were mainly given with contact-therapy using a $50 \mathrm{kV}$ peak with a $1 \mathrm{~mm} \mathrm{Al} \mathrm{filter,} \mathrm{and} \mathrm{a} \mathrm{short} \mathrm{focus} \mathrm{distance.} \mathrm{The}$ radiotherapy technique chosen depended on the surface and on the thickness of the hemangioma [19].

The preliminary studies [3,5] on radiation-induced effects on the skin and thyroid following treatment for skin hemangioma in childhood, were based on simplified dose calculation models. These models were specific to the sites studied but could not be adjusted for the estimation of doses delivered to other sites in the body in accordance with the European cohort study requirements. The ICTA software was developed for this purpose. ICTA stands for Individualized phantom based on CT slices of a real human body, using Auxological data. Individuals of various ages and the different applicators used to treat skin 
hemangiomas can be simulated with this software and all radium and beta applicator characteristics are included. These applicators are placed on the patient according to the information found in the patient's file (drawing, description, photographs). Doses delivered to 151 anatomical landmarks distributed throughout the body can be estimated with the ICTA dose calculation algorithm. The general structure of the ICTA software has previously been described [20], and the simulation of individuals has been detailed elsewhere [13]. The dose calculation algorithm integrated into ICTA for ${ }^{226} \mathrm{Ra}$ and pure beta emission isotopes $\left({ }^{32} \mathrm{P}\right.$, ${ }^{90} \mathrm{Sr} /{ }^{90} \mathrm{Y},{ }^{90} \mathrm{Y}$ ), and the comparison for ${ }^{226} \mathrm{Ra}$ sources with Swedish results obtained at Radiumhemmet, Karolinska Hospital, have been published [21]. The absorbed doses at 151 anatomical points, including 91 bony points, were calculated with ICTA for each patient, each treated hemangioma, and each RT session and recorded in the dose database.

Similar calculations were performed for x-ray treatments using Dos_EG [4] and the detailed dose data were recorded in the dose database. For patients with more than one radiotherapy session, the doses calculated at the same site for the different sessions were summed up and recorded as the estimated dose delivered to that site for a given patient and were used to correlate doses to possible effects, if any.

The mean doses to the brain (7 points of estimation), eye (1 point of estimation by eye), breast ( 1 point of estimation by breast), thyroid ( 2 points of estimation), colon ( 5 points of estimation), and lung (5 points of estimation by lung) were, respectively, $80 \mathrm{mGy}, 140 \mathrm{mGy}$, $80 \mathrm{mGy}, 40 \mathrm{mGy},<10 \mathrm{mGy}$ and $30 \mathrm{mGy}$ (Table 2). The weighted average active bone marrow dose was calculated from the doses estimated for the 91 points of the skeleton, using age-dependent coefficients for 20 parts of the body published by Cristy [2]. The effective dose was calculated using coefficients published in ICRP Report 73 [10]. The effective dose is defined in ICRP Report 60 as a summation of the equivalent doses for organs, with the term for each organ multiplied by an appropriate tissue weighting factor [9].

\section{Statistical analysis}

The period at risk for each subject began from the initiation of hemangioma treatment or January $1^{\text {st }} 1969$, if treated before this date, and ended at the time of death or January $1^{\text {st }}$ 1998. Before 1969, 18978 persons-years of follow-up were lost, 69\% of which concerned female patients, $83 \%$ in patients under 1 year of age when treated and $67 \%$ in patients who had received radiotherapy.

Reference mortality rates, according to sex, calendar year, age, and cause of death, in the general French population were obtained from the CépiDc INSERM, as well as the abovementioned causes of death in our series, in order to estimate the standardized mortality ratio 
(SMR). These national mortality rates were used because the patients now live all over France.

Both external and internal analyses were performed. The SMR variations according to radiotherapy or not, sex, age at first treatment, date of treatment, year of follow-up, attained age and calendar year were studied assuming Poisson distribution of the expected number of deaths [1]. The 95\% CI confidence intervals were calculated using maximum likelihood methods [17]. Calculations were made using AMFIT® ${ }^{\circledR}$ software [18]. SMR and relative risk (RR) variations according to radiotherapy or not, the type of treatment and the effective dose were then studied.

\section{RESULTS}

Between 1969 to 1997, 123 patients died in the cohort, of whom 85 had received radiotherapy (Table 3). No excess of total deaths was observed for patients who had received radiotherapy compared to the general population $(\mathrm{SMR}=0.99 ; 95 \% \mathrm{CI}=0.79-1.22)$. The same result was observed for patients who had not received radiotherapy compared to the general population $(\mathrm{SMR}=0.96 ; 95 \% \mathrm{CI}=0.69-1.30)$.

During this period, 18 patients in the cohort, 15 of whom had received radiotherapy, had there initial, immediate and associated causes of death recorded as "symptoms, signs and ill-defined conditions". For this category, compared to the general population, there was a significant excess of mortality among irradiated patients $(\mathrm{SMR}=2.2 ; 95 \% \mathrm{CI}=1.2-3.4)$ (Table 3).

During this period, 16 patients in the cohort died of cancer, 14 of whom had received radiotherapy (Table 3). A non significant excess of cancer-related mortality was observed for patients who had received radiotherapy as compared to the general population (SMR $=1.53$; $95 \% \mathrm{CI}=0.86-2.48)$. No excess mortality due to cancer was observed for patients without radiotherapy as compared to the general population ( $\mathrm{SMR}=0.45 ; 95 \% \mathrm{CI}=0.08-1.40)$. Of the 14 cancer-related deaths after radiotherapy, 3 were due to a brain tumor (expected [exp] = $1.1), 4$, a digestive tumor $(\exp =0.7), 1$, leukemia $(\exp =2.3), 2$, a respiratory tumor $(\exp =$ $0.5), 1$, an ovary tumor $(\exp =0.5), 1$, a testis tumor $(\exp =0.2), 1$, melanoma $(\exp =0.4)$ and 1 patient died of an unspecified cancer.

Compared to the general population, the analysis of the other major causes of death among irradiated patients, as defined by the World Health Organization, evidenced a significant deficit of mortality due to external causes (SMR $=0.67 ; 95 \% \mathrm{CI}=0.46-0.94)$ and 
a significant excess of mortality due to symptoms, signs and ill-defined conditions (SMR = 2.2 ; 95\% CI = 1.2-3.4) (Table 3).

No significant variation was observed in the SMR for total deaths and cancer-related mortality according to sex, age at $1^{\text {st }}$ treatment, date of $1^{\text {st }}$ treatment, follow-up, and attained age, both for patients who had been treated with radiotherapy and those who had not.

Among patients treated with ${ }^{226} \mathrm{Ra}$, there was a non significant excess of total and cancer mortality as compared to the general population $\left(\mathrm{SMR}_{\text {total death }}=1.31\right.$; $95 \% \mathrm{CI}=0.89-1.86),\left(\mathrm{SMR}_{\text {cancer death }}=2.50 ; 95 \% \mathrm{CI}=0.99-5.07\right)$. When the role of other treatments (x-rays, ${ }^{32} \mathrm{P},{ }^{90} \mathrm{Sr} /{ }^{90} \mathrm{Yr},{ }^{90} \mathrm{Yr}$ ) some patients had received was taken into account, treatment with ${ }^{226} \mathrm{Ra}$ appeared to play a significant role in the excess mortality compared to no radiotherapy $\left(\mathrm{RR}_{\text {total death }}=1.52 ; 95 \% \mathrm{CI}=0.95-2.36\right),\left(\mathrm{RR}_{\text {cancer death }}=2.53 ; 95 \% \mathrm{CI}=0.84\right.$ 7.07). The other types of irradiation (beta and x-rays) had no effect.

The average effective dose among patients who had received radiotherapy was $22 \mathrm{mSv}$ and the median value was $0.1 \mathrm{mSv}$. Eight patients received an effective dose that was higher than $1 \mathrm{~Sv}$. Of these 8 patients, 4 were treated with X-rays alone, 2 with $\mathrm{X}$-rays, ${ }^{226} \mathrm{Ra}$, and ${ }^{32} \mathrm{P}$, 1 with X-rays and ${ }^{90} \mathrm{Sr}$, and 1 with ${ }^{226} \mathrm{Ra}$ alone.

After stratifying on other variables, no evidence was found for a relation between the effective dose of radiation and the risk of cancer-related mortality $\left(\chi^{2}=115.13-114.99=\right.$ 0.14). Table 4 describes the doses received at the cancer site for the 14 cancer deaths, as well as the effective and maximum dose for these patients.

\section{DISCUSSION}

Based on the 85 deaths in the radiotherapy group, 14 of which occurred during the 31 years of follow-up and were due to cancer, we evidenced a non significant excess of mortality following treatment with ${ }^{226} \mathrm{Ra}$, but not for patients who had received $\mathrm{x}$-rays, ${ }^{32} \mathrm{P},{ }^{90} \mathrm{Sr},{ }^{90} \mathrm{Yr}$. We were unable to establish a dose-response relation between the effective dose and all causes and cancer mortality.

Potential biases may limit the interpretation of our results. A total of 763 (10\%) patients were excluded from this study because we were unable to obtain their vital status. The identification data in the IGR medical records concerning these patients did not match those obtained from the INSEE. As the quality of the identification data in the medical records was likely linked to the number of consultations at the IGR, during which information could have been updated, patients with poor quality identification data probably underwent fewer 
consultations than the others. However, as included and excluded patients were comparable, this bias is probably low (Table 1).

There is an apparent contradiction between the significant excess of cancer mortality in patients who had received radiotherapy, in particular with ${ }^{226} \mathrm{Ra}$ sources, and the absence of a dose-response relation for the effective dose values. In addition, the effective dose, the maximal dose and the dose estimated at the cancer site were all lower than the corresponding mean values in the radiotherapy group. This discrepancy could be due to several reasons. Firstly, the observed excess mortality, only significant for radiotherapy and well nigh significant for ${ }^{226} \mathrm{Ra}$, could be due to chance. Secondly, the effective dose is not a good indicator of the radiation dose, if irradiation is heterogeneous. This plausible explanation is nevertheless partly counterbalanced by our results for the maximal dose at any site, and the dose at the cancer site. Other reasons may be due to uncertainties in dose estimation due to unavailable data, e.g. unknown position of patients during treatments. One of the dosimetric parameters is the source-target distance which was calculated assuming patients were lying down during the treatment session. If the patient had been sitting, this would have led to an overestimation of the source-site distance.

The doses estimated to the main organs of the body delivered by ${ }^{226} \mathrm{Ra}$ sources were higher than those delivered by ${ }^{32} \mathrm{P},{ }^{90} \mathrm{Sr},{ }^{90} \mathrm{Yr}$ but lower than those delivered by $\mathrm{x}$-rays. Caution should be exercised when interpreting the excess of cancer-related mortality among patients who had received ${ }^{226} \mathrm{Ra}$, as compared to the others. Indeed, these patients had a longer follow-up, and were, on average, 35 years old (11-59) at the end of the follow-up, compared to 31 years (0-59) on average for the others. Notwithstanding, we did not evidence an increased SMR with attained age ; the shorter follow-up in other patients reduces the capacity to evidence an excess and thus could account for this difference.

It is not possible for us to estimate the relation between the organ dose and the later risk of cancer-related death due to the small number of cancer-related deaths in our cohort (a total of 14) and to the variability of the organs in which these fatal cancers developed, [1 death for each type of organ, except for the brain (3 deaths) and pancreas (2 deaths)].

Except for the brain, the average organ dose we estimated for patients treated with ${ }^{226} \mathrm{Ra}$ was at least 2-fold lower than that estimated in the Stockholm and Gotenburg cohort studies (Table 5). This difference is in part explained by a variation in the treatment periods: Swedish patients had been treated between 1920 and 1965, 90\% of them between 1940 and 1959, whereas, in our cohort, patients had been treated between 1940 and 1973, $98 \%$ of them between 1960 and 1973. This difference, nonetheless, persisted when the comparison was 
restricted to the Swedish patients treated from 1950-1959, and we did not observe a decrease in organ radiation doses with calendar time of treatment in our cohort.

The excess of cancer $(\mathrm{SMR}=1.53$ [0.86-2.48]) is compatible with that observed in the Stockholm cohort (SMR=1.34 [1.11-1.60]). Interestingly, only 1 leukemia was observed in our cohort (2.3 expected), although a minimum of 25 years of follow-up is sufficient to observe all the radio-induced leukemia cases that are expected to appear less than 15 years after early irradiation in childhood. This result should be compared to the non significant excess of leukemia found in the Stockholm cohort (SMR=1.40 [0.79-2.31]) [7]. We did not find excess mortality due to external causes (trauma) (Table 4), unlike that observed in the Swedish cohort [7]. We have no explanation for the excess of deaths from "symptoms, signs and ill-defined conditions" which is not linked to the quality of the data since the national database of causes of death was used both to compute the reference rates and to identify the causes of death in our cohort.

At the end of the follow-up, the patients in our cohort were still young, 31 years on average (0-59). Only 9.1 cancer-related deaths were expected in our cohort, as compared to 91 in the Stockholm cohort. In addition to the young age of patients at the end of the followup, we studied cancer mortality rather than cancer incidence, thus reducing the power to detect an excess for all cancer sites together. For tumors with a good prognosis (e.g. breast and thyroid [3]), which were more likely to have been irradiated in our cohort, the power to detect excess mortality is very low in our study.

Our analysis was able to detect a SMR of 2 or higher with a reasonable power (80\%). Such a SMR was unexpected in our cohort, due to the average effective dose of $20 \mathrm{mSv}$. On the other hand, during the following 20 years (1997-2017), a total of 70 cancer-related deaths are expected in our cohort after radiotherapy, in the absence of an increased risk of cancerrelated mortality. It will then be possible to detect a SMR of 1.3. Such an increase of $30 \%$ is what was observed in the Stockholm cohort [7], with the doses received by most organs attaining about 4-fold higher than that observed in our cohort.

In conclusion, this study suggests an excess risk of cancer-related mortality in patients treated during early childhood with radiotherapy for skin hemangioma, especially with ${ }^{226} \mathrm{Ra}$. Moreover, the Swedish experience shows that these patients should be followed-up because they are at an increased risk of developing a cancer in the future. 


\section{REFERENCES}

[1] Breslow NE, Day NE. Statistical methods in cancer research. Vol 2. The design and analysis of cohort studies. International Agency for Research on Cancer: Lyon 1987.

[2] Cristy M. Active bone marrow distribution as a function of age in humans. Phys Med Biol 1981; 26(3):389-400.

[3] de Vathaire F, Fragu P, Francois $\mathrm{P}$ et al. Long-term effects on the thyroid of irradiation for skin angiomas in childhood. Radiat Res 1993; 133(3):381-386.

[4] Diallo I, Lamon A, Shamsaldin A, Grimaud E, de Vathaire F, Chavaudra J. Estimation of the radiation dose delivered to any point outside the target volume per patient treated with external beam radiotherapy. Radiother Oncol 1996; 38(3):269-271.

[5] Fragu P, Lemarchand-Venencie F, Benhamou S et al. Long-term effects in skin and thyroid after radiotherapy for skin angiomas: a French retrospective cohort study. Eur J Cancer 1991; 27(10):1215-1222.

[6] Furst CJ, Lundell M, Holm LE. Radiation therapy of hemangiomas, 1909-1959. A cohort based on 50 years of clinical practice at Radiumhemmet, Stockholm. Acta Oncol 1987; 26(1):33-36.

[7] Furst CJ, Silfversward C, Holm LE. Mortality in a cohort of radiation treated childhood skin hemangiomas. Acta Oncol 1989; 28(6):789-794.

[8] Furst CJ, Lundell M, Holm LE. Tumors after radiotherapy for skin hemangioma in childhood : a case control study. Acta Oncol 1990; 29(5):557-562.

[9] ICRP International Commission of Radiological Protection. ICRP Publication 60. 1990 Recommendations of the International Commission on Radiological Protection. Pergamon Press, Oxford, UK 1991.

[10] ICRP International Commission of Radiological Protection. ICRP Publication 73. Radiological Protection and Safety in Medecine. Pergamon Press, Oxford, UK 1996.

[11] Karlsson P, Holmberg E, Lundell M, Mattsson A, Holm LE, Wallgren A. Intracranial tumors after exposure to ionizing radiation during infancy: a pooled analysis of two Swedish cohorts of 28,008 infants with skin hemangioma. Radiat Res 1998; 150(3):357-364.

[12] Li FP, Cassady JR, Barnett E. Cancer mortality following irradiation in infancy for hemangioma. Radiology 1974; 113(1):177-178.

[13] Ligot L, Diallo I, Shamsaldin A, Chavaudra J, Bonaiti-Pellie C, de Vathaire F. Individualized phantom based on CT slices and auxological data (ICTA) for dose estimations following radiotherapy for skin haemangioma in childhood. Radiother Oncol 1998; 49(3):279-285.

[14] Lindberg S, Karlsson P, Arvidsson B, Holmberg E, Lunberg LM, Wallgren A. Cancer incidence after radiotherapy for skin haemangioma during infancy. Acta Oncol 1995; 34(6):735-740. 
[15] Lundell M. Estimates of absorbed dose in different organs in children treated with radium for skin hemangiomas. Radiat Res 1994; 140(3):327-333.

[16] Lundell M, Mattsson A, Karlsson P, Holmberg E, Gustafsson A, Holm LE. Breast cancer risk after radiotherapy in infancy: a pooled analysis of two Swedish cohorts of 17,202 infants. Radiat Res 1999; 151(5):626-632.

[17] Moolgavkar SH, Venzon DJ. A method for computing profile likelihood based confidence bounds. Ann Stat 1987; 15:346-349.

[18] Preston DL, Lubin JH, Pierce DA, McConney ME. EPICURE. Generalized regression models for epidemiological data. HiroSoft International Corporation: Seattle (WA) 1991.

[19] Sancho H, Beyer HP. Skin tumors. In: Bloom J, Lemerle J, Neider N, editors. Cancer in Children, Clinical Management. Berlin: Springer, 1975: 273-283.

[20] Shamsaldin A, Diallo I, Ligot L, Chavaudra J, de Vathaire F. Knowledge of doses from radiumtherapy for skin hemangioma in childhood. IAEA Technical Document 1997; 976:91-93.

[21] Shamsaldin A, Lundell M, Diallo I, Ligot L, Chavaudra J, de Vathaire F. Estimation of the radiation dose from radiotherapy for skin haemangiomas in childhood: the ICTA software for epidemiology. Phys Med Biol 2000; 45(12):3589-3599. 
Table 1: Characteristics of the 7800 patients treated for a hemangioma from 1940 to 1973 under 15 years of age at Institut Gustave-Roussy

\begin{tabular}{|c|c|c|}
\hline & $\begin{array}{l}\text { Included patients } \\
\qquad(\mathrm{n}=7037)\end{array}$ & $\begin{array}{l}\text { Excluded patients } \\
\qquad(\mathrm{n}=763)\end{array}$ \\
\hline Characteristics & Number (\%) & Number (\%) \\
\hline Women & $4813(68 \%)$ & $534(70 \%)$ \\
\hline \multicolumn{3}{|l|}{ Age at $1^{\text {st }}$ treatment } \\
\hline$<1$ & 5770 (82\%) & 587 (77\%) \\
\hline $1-3$ & 801 (11\%) & 104 (14\%) \\
\hline $3-5$ & $140(2 \%)$ & $17(2 \%)$ \\
\hline $5-10$ & $187(3 \%)$ & $37(5 \%)$ \\
\hline $10-15$ & $139(2 \%)$ & $18(2 \%)$ \\
\hline \multicolumn{3}{|l|}{ Date of treatment } \\
\hline 1940-1950 & $53(1 \%)$ & $7(1 \%)$ \\
\hline $1950-1960$ & $174(2 \%)$ & $26(3 \%)$ \\
\hline 1960-1970 & 4749 (68\%) & 509 (67\%) \\
\hline 1970-1973 & 2061 (29\%) & 221 (29\%) \\
\hline Radiotherapy & $4940(70 \%)$ & $533(70 \%)$ \\
\hline Dose estimation completed $^{1}$ & $4740(96 \%)$ & 497 (93\%) \\
\hline \multicolumn{3}{|l|}{ Type $\mathrm{e}^{1,2}$} \\
\hline${ }^{226} \mathrm{Ra}$ & 1072 (23\%) & 113 (23\%) \\
\hline X-Rays & $568(12 \%)$ & 76 (15\%) \\
\hline${ }^{32} \mathrm{P}$ & $940(20 \%)$ & 99 (20\%) \\
\hline${ }^{90} \mathrm{Sr}$ & 3125 (66\%) & $296(60 \%)$ \\
\hline${ }^{90} \mathrm{Yr}$ & $361(8 \%)$ & $31(6 \%)$ \\
\hline \multicolumn{3}{|l|}{ Effective dose (mSv) ${ }^{1}$} \\
\hline$<10$ & 3509 (74\%) & $354(71 \%)$ \\
\hline 10 to $<100$ & 989 (21\%) & 111 (22\%) \\
\hline 100 to $<1000$ & $234(5 \%)$ & $31(6 \%)$ \\
\hline$\geq 1000$ & $8(0.2 \%)$ & $1(0.2 \%)$ \\
\hline
\end{tabular}

${ }^{1}$ in patients who received doses

${ }^{2} 24 \%$ of patients were treated with more than one technique

Ra: Radium ; P: Phosphor ; Sr: Strontium ; Yr: Yttrium. 
Table 2: Treatment period, follow-up, doses to main organs in Grays and effective dose in Sieverts according to the type of treatment among the 4740 patients* treated with radiotherapy for a hemangioma at Institut Gustave-Roussy.

\begin{tabular}{|c|c|c|c|c|c|c|c|}
\hline Type of treatment & ${ }^{226} \mathrm{Ra}$ & $\mathrm{X}$-rays & ${ }^{32} \mathrm{P}$ & & ${ }^{90} \mathrm{Sr}$ & ${ }^{90} \mathrm{Yr}$ & All treatments \\
\hline & mean (min-max) & mean (min-max) & mean (min-max) & mean & $(\min -\max )$ & mean (min-max) & mean (min-max) \\
\hline $\mathrm{N}$ & 1072 & 568 & 940 & 3125 & & 361 & 4740 \\
\hline Treatment period & 1962 (1941-1973) & 1966 (1944-1973) & 1966 (1949-1973) & 1968 & (1950-1973) & 1967 (1941-1973) & 1967 (1941-1973) \\
\hline Follow-up (years) & $35(11-59)$ & $32(20-59)$ & $33(4-51)$ & 30 & $(0-51)$ & $30(15-58)$ & $31(0-59)$ \\
\hline \multicolumn{8}{|l|}{ Radiation dose (Gy) } \\
\hline Brain & $0.13(<0.01-5.6)$ & $0.32(<0.01-10.9)$ & $0.01 \quad(<0.01-1.0)$ & 0.01 & $(<0.01-1.4)$ & $<0.01 \quad(<0.01-0.4)$ & $0.08 \quad(<0.01-10.9)$ \\
\hline Eye & $0.21(<0.01-23.3)$ & $0.55(<0.01-19.7)$ & $0.03(<0.01-2.6)$ & 0.03 & $(<0.01-5.8)$ & $0.01 \quad(<0.01-1.3)$ & $0.14(<0.01-23.3)$ \\
\hline Breast & $0.11(<0.01-22.7)$ & $0.16(<0.01-13.1)$ & $0.01 \quad(<0.01-1.8)$ & 0.04 & $(<0.01-8.5)$ & $0.10(<0.01-6.8)$ & $0.08 \quad(<0.01-22.7)$ \\
\hline Thyroid & $0.05(<0.01-3.0)$ & $0.20(<0.01-7.8)$ & $<0.01 \quad(<0.01-0.9)$ & $<0.01$ & $(<0.01-2.2)$ & $<0.01 \quad(<0.01-0.3)$ & $0.04(<0.01-7.8)$ \\
\hline Colon & $0.02(<0.01-1.4)$ & $0.04(<0.01-4.2)$ & $<0.01 \quad(<0.01-<0.01)$ & $<0.01$ & $(<0.01-0.02)$ & $<0.01 \quad(<0.01-<0.01)$ & $<0.01 \quad(<0.01-4.2)$ \\
\hline Lung & $0.06(<0.01-2.0)$ & $0.13(<0.01-6.4)$ & $<0.01 \quad(<0.01-0.02)$ & $<0.01$ & $(<0.01-0.2)$ & $<0.01 \quad(<0.01-0.03)$ & $0.03(<0.01-6.4)$ \\
\hline Active bone marrow & $0.06(<0.01-4.4)$ & $0.16(<0.01-3.4)$ & $<0.01 \quad(<0.01-0.2)$ & $<0.01$ & $(<0.01-0.3)$ & $<0.01 \quad(<0.01-0.3)$ & $0.04(<0.01-4.4)$ \\
\hline Effective dose (Sv) & $0.04(<0.01-1.8)$ & $0.09 \quad(<0.01-3.0)$ & $<0.01 \quad(<0.01-0.1)$ & $<0.01$ & $(<0.01-1.0)$ & $<0.01 \quad(<0.01-0.3)$ & $0.02(<0.01-3.0)$ \\
\hline
\end{tabular}


Table 3: Number of observed and expected deaths, for patients without radiotherapy and patients with radiotherapy.

\begin{tabular}{|c|c|c|c|c|}
\hline & No rad & eerapy & Radi & erapy \\
\hline & Obs & Exp & Obs & Exp \\
\hline All deaths & 38 & 39.4 & 85 & 85.8 \\
\hline Cancer deaths (ICD9 : 140-209) & 2 & 4.4 & 14 & 9.1 \\
\hline All deaths except cancer & 34 & 35.0 & 64 & 76.6 \\
\hline Cause of death not found* & 2 & & 7 & \\
\hline Infectious and Parasitic Diseases (ICD9: 001-139) & 1 & 0.7 & 5 & 1.5 \\
\hline Malignant Neoplasms (ICD9 : 140-209) & 2 & 4.4 & 14 & 9.1 \\
\hline Neoplasms excepted cancer (ICD9 : 210-239) & 4 & 0.5 & 2 & 1.2 \\
\hline Endocrine, Nutritional and Metabolic Diseases (ICD9: 240-279) & 0 & 2.5 & 0 & 5.5 \\
\hline Diseases of the Blood and Blood-forming Organs (ICD9: 280-289) & 0 & 0.2 & 0 & 0.6 \\
\hline Mental Disorders (ICD9: 290-319) & 2 & 0.7 & 1 & 1.4 \\
\hline Diseases of the Nervous System and Sense Organs (ICD9: 320-389) & 1 & 1.4 & 3 & 3.1 \\
\hline Diseases of the Circulatory System (ICD9: 390-459) & 3 & 2.1 & 0 & 4.3 \\
\hline Diseases of the Respiratory System (ICD9: 460-519) & 1 & 1.1 & 1 & 2.4 \\
\hline Diseases of the Digestive System (ICD9: 520-579) & 1 & 0.9 & 2 & 1.5 \\
\hline Diseases of the Genitourinary System (ICD9: 580-629) & 0 & 0.2 & 1 & 0.3 \\
\hline Obstetric Complications (ICD9: 630-677) & 0 & 0.2 & 0 & 0.4 \\
\hline Diseases of the Skin and Subcutaneous Tissue (ICD9: 680-709) & 0 & 0.0 & 0 & 0.1 \\
\hline Diseases of the Musculoskeletal System and Connective Tissue (ICD9: 710-739) & 0 & 0.1 & 1 & 0.2 \\
\hline Congenital Anomalies (ICD9: 740-759) & 0 & 1.0 & 1 & 2.4 \\
\hline Certain Conditions originating in the Perinatal Period (ICD9: 760-779) & 1 & 0.0 & 2 & 0.0 \\
\hline Symptoms, Signs and Ill-defined Conditions (ICD9: 780-799) & 3 & 3.2 & 15 & 6.9 \\
\hline External Causes (ICD9: 800-999) & 17 & 20.4 & 30 & 44.8 \\
\hline Neoplasms excepted cancer : benign tumor of endocrine gland (ICD9: 227.9) & 1 & & 2 & \\
\hline Neoplasms excepted cancer : hemangioma (ICD9: 228.0) & 3 & & 0 & \\
\hline Person Years & & & & \\
\hline
\end{tabular}

* The vital status of patients has been assessed, but matching with the national database of causes of death was not possible, probably because of errors in identification. 
Table 4: Characteristics of the 14 cases of cancer-related death after radiotherapy

\begin{tabular}{|c|c|c|c|c|c|c|c|c|}
\hline \multirow[t]{2}{*}{ Cancer site } & \multirow[t]{2}{*}{ Sex } & \multirow{2}{*}{$\begin{array}{l}\text { Age at 1st } \\
\text { treatment } \\
\text { (years) }\end{array}$} & \multicolumn{2}{|c|}{ Year of } & \multirow[t]{2}{*}{ Type of exposure } & \multirow{2}{*}{$\begin{array}{r}\text { Effective } \\
\text { dose }^{1} \\
(\mathrm{mSv})\end{array}$} & \multirow{2}{*}{$\begin{array}{r}\text { Maximum } \\
\text { dose }^{2} \\
(\mathrm{mGy})\end{array}$} & \multirow{2}{*}{$\begin{array}{r}\text { Dose to } \\
\text { cancer site }^{3} \\
(\mathrm{mGy})\end{array}$} \\
\hline & & & treatment & death & & & & \\
\hline Liver (155.0) & Male & 0 & 1959 & 1987 & $?$ & $?$ & ? & ? \\
\hline Pancreas (157.9) & Female & 0 & 1960 & 1977 & Ra226 + Sr90 & 0.3 & 206 & 0.01 \\
\hline Pancreas (157.9) & Female & 11 & 1966 & 1992 & P32 & $<0.01$ & 2280 & $<0.01$ \\
\hline Peritoneum(158.0) & Male & 0 & 1960 & 1996 & Ra226 & 2.9 & 78 & ? \\
\hline Lung (162.9) & Female & 14 & 1961 & 1992 & $\mathrm{Kv}$ & 4.1 & 870 & 0.7 \\
\hline Mediastinum (164.9) & Male & 0 & 1964 & 1991 & Sr90 & $<0.01$ & 10 & ? \\
\hline Skin (172.9) & Female & 0 & 1965 & 1984 & Sr90 & $<0.01$ & 2880 & ? \\
\hline Ovaries (183.0) & Female & 0 & 1963 & 1977 & Ra226 + Sr90 & 9.4 & 897 & 0.4 \\
\hline Testis (186.9) & Male & 0 & 1966 & 1989 & $\mathrm{P} 32+\mathrm{Sr} 90+$ Yr90 & 0.2 & 507 & 0 \\
\hline Brain (192.9) & Female & 0 & 1963 & 1993 & Ra226 & 25.8 & 870 & 83.1 \\
\hline Brain (191.9) & Male & 1 & 1968 & 1978 & Sr90 & $<0.01$ & 0 & 0 \\
\hline Brain (191.0) & Female & 0 & 1968 & 1982 & Sr90 & $<0.01$ & 2.2 & 0 \\
\hline Leukemia (207.0) & Female & 0 & 1964 & 1975 & Ra226 + P32 & 1.7 & 263 & 7.4 \\
\hline Unspecified (199.0) & Male & 0 & 1959 & 1992 & Ra226 & 5.9 & 1320 & ? \\
\hline
\end{tabular}

1 effective dose for the cohort (mean ; median) : (22 mSv; $0.1 \mathrm{mSv})$

${ }^{2}$ maximum dose to any site for the cohort (mean ; median) : (1300 mGy; $\left.82 \mathrm{mGy}\right)$

${ }^{3}$ doses to the following sites for the cohort (mean ; median) : pancreas (12 mGy ; <0.01 mGy), lung (30 mGy ; <0.01 mGy), ovaries (4 mGy ; <0.01 mGy), testis (20 mGy ; <0.01 mGy), brain (79 mGy ; <0.01 mGy) and bone marrow (37 mGy ; 0.4 mGy) 
Table 5: Doses received by the main organs in our cohort and Swedish cohorts.

\begin{tabular}{lccccc}
\hline \multirow{2}{*}{ Site } & \multicolumn{7}{c}{ Dose (Gy) } \\
\cline { 2 - 6 } & \multicolumn{7}{c}{ Villejuif cohort } & Stockholm cohort & Gothenburg cohort \\
\cline { 2 - 6 } & \multicolumn{7}{c}{ All treatments } & \multicolumn{2}{c}{ (Lundell 1994) [15] } & (Lindberg 1995) [14] \\
\cline { 2 - 6 } & 0.08 & $(<0.01-10.9)$ & $0.13(<0.01-5.6)$ & $0.07 \quad(<0.01-2.6)$ & 0.07 \\
\hline Brain & 0.08 & $(<0.01-22.7)$ & $0.11(<0.01-22.7)$ & $0.48 \quad(<0.01-47.7)$ & 0.16 \\
Breast & 0.04 & $(<0.01-7.8)$ & $0.05(<0.01-3.0)$ & $0.29 \quad(<0.01-19.0)$ & 0.12 \\
Thyroid & $<0.01$ & $(<0.01-4.2)$ & $0.02(<0.01-1.4)$ & $0.09 \quad(<0.01-5.9)$ & 0.12 \\
Colon & 0.03 & $(<0.01-6.4)$ & $0.06(<0.01-2.0)$ & $0.15 \quad(<0.01-4.3)$ & \\
Lung & 0.04 & $(<0.01-4.4)$ & $0.06(<0.01-4.4)$ & $0.16 \quad(<0.01-6.0)$ & \\
Active bone marrow & $0.04)$ &
\end{tabular}

